\title{
Extracellular matrix composition defines an ultra-high-risk group of neuroblastoma within the high-risk patient cohort
}

\author{
Irene Tadeo ${ }^{1}$, Ana P Berbegall ${ }^{1}$, Victoria Castel ${ }^{2}$, Purificación García-Miguel ${ }^{3}$, Robert Callaghan ${ }^{1}$, \\ Sven Påhlman ${ }^{4}$, Samuel Navarro ${ }^{1}$ and Rosa Noguera*,1 \\ 'Department of Pathology, Medical School, University of Valencia - INCLIVA, Avda. Blasco Ibañez 15, 46010 Valencia, Spain; \\ ${ }^{2}$ Pediatric Oncology Unit, University and Polytechnic Hospital La Fe, Avda. Fernando Abril Martorell 106, 46026, Valencia, Spain; \\ ${ }^{3}$ Service of Pediatric Oncohematology, University Hospital La Paz, Paseo de la Castellana 261, 28046 Madrid, Spain and ${ }^{4}$ Division \\ of Molecular Medicine Medicon Village, Building 406 Lund University, SE-223 81 Lund, Sweden
}

Background: Although survival for neuroblastoma patients has dramatically improved in recent years, a substantial number of children in the high-risk subgroup still die.

\begin{abstract}
Methods: We aimed to define a subgroup of ultra-high-risk patients from within the high-risk cohort. We used advanced morphometric approaches to quantify and characterise blood vessels, reticulin fibre networks, collagen type I bundles, elastic fibres and glycosaminoglycans in 102 high-risk neuroblastomas specimens. The Kaplan-Meier method was used to correlate the analysed elements with survival.
\end{abstract}

Results: The organisation of blood vessels and reticulin fibres in neuroblastic tumours defined an ultra-high-risk patient subgroup with 5-year survival rate $<15 \%$. Specifically, tumours with irregularly shaped blood vessels, large sinusoid-like vessels, smaller and tortuous venules and arterioles and with large areas of reticulin fibres forming large, crosslinking, branching and haphazardly arranged networks were linked to the ultra-high-risk phenotype.

Conclusions: We demonstrate that quantification of tumour stroma components by morphometric techniques has the potential to improve risk stratification of neuroblastoma patients.

Neuroblastoma (NB) is an extremely heterogeneous paediatric tumour accounting for $15 \%$ of childhood deaths from cancer (Ambros et al, 2009; Cohn et al, 2009). Although survival has dramatically improved in the past decades, there is still a great need to improve patient survival, especially in the subgroup of high-risk patients. This subgroup is defined by presence of tumour $M Y C N$ amplification or children with metastatic disease older than age 18 months at diagnosis (Cohn et al, 2009; Saarinen-Pihkala et al, 2013). The fundamental biological processes leading to high-risk $\mathrm{NB}$ are of key importance. A better understanding of these processes, including the regulatory pathways controlling $M Y C N$ activity, would lead to improved stratification of the high-risk patients, and could form the basis for new therapeutic strategies to enhance survival. Tumour angiogenesis is now widely accepted as essential for tumour growth and metastasis (Folkman et al, 1971; Maiese, 2012). In many aspects, tumour vessels are different from normal vessels; they are dilated, tortuous and poorly covered by pericytes (Carmeliet and Jain, 2000; Bergers and Benjamin, 2003). In $\mathrm{NB}$, conflicting results have been reported with regard to the prognostic impact of angiogenesis (Canete et al, 2000; Peddinti et al, 2007; Jakovljevic et al, 2011; Tadeo et al, 2013, 2016).

The architectural role of the fibrous component of the extracellular matrix (ECM) is clear and central for tissue homeostasis (Ushiki, 2002). In fact, scaffold architecture has been found

*Correspondence: Professor R Noguera; E-mail: rnoguera@uv.es

Received 5 April 2016; revised 8 June 2016; accepted 15 June 2016; published online 14 July 2016

(c) 2016 Cancer Research UK. All rights reserved 0007-0920/16 
to have a significant impact on cell growth ( $\mathrm{Ng}$ and Brugge, 2009; Lowery et al, 2010). Reticulin fibres (Ret Fs), composed of type III collagen, are thin fibres arranged as loose meshworks and providing a supportive scaffolding for certain organs. These fibres not only influence morphological changes of the cell, but also various biological functions in NB (Liu et al, 2005). Collagen type I fibres (Col I Fs) usually form thick bundles following a wavy course without branching in connective tissue of skin, bone and organ capsules, among others. Of relevance to $\mathrm{NB}$, an aligned collagen fibre matrix enhances differentiation of human neural crest stem cells towards the Schwann cell lineage while increased collagen crosslinking is a significant contributor to the changes in cellular mechanical microenvironment that accompanies tumour progression (Ng and Brugge, 2009; Ren et al, 2013). The role of elastic fibres (EFs) in neoplastic processes has not been reported to any extent, although a relationship between fibre density and tumour progression has been found in some malignancies (Devy et al, 2012; Toupance et al, 2012). Finally, glycosaminoglycans (GAGs) have biofiltering, scaffolding and cell anchoring properties and have been implicated in diverse malignancies (Karamanos and Tzanakakis, 2012). Therefore, they are now understood as key players in cancer development and are novel therapeutic agents (Afratis et al, 2012).

Tumour cells are able to alter the mechanical properties of the microenvironment to create favourable conditions for their proliferation and/or dissemination (DuFort et al, 2010). ECM stiffness also indirectly affects tumour pathophysiology by deforming blood vessels, as described in pancreatic cancer. The compression of tumour vasculature also leads to a reduction in tumour blood flow and subsequently reduces the anticancer agent transport to tumour cells (Padera et al, 2004). ECM stiffness has been implicated in processes relevant to aggressive NB phenotype(s), such as stage of neuronal maturation, $M Y C N$ expression and malignant potential (Lam et al, 2010). In vitro studies further show that $\mathrm{NB}$ cells respond differently to a $3 \mathrm{D}$ than a $2 \mathrm{D}$ environment and that the regulation of gene expression and morphology depends on the geometry of the matrix as well as on its composition, structure and mechanical properties (Li et al, 2007; Lovett et al, 2013). Consequently, ECM can be understood not only as a reactive neighbour, but should also be considered as a main actor in these processes (Hu and Polyak, 2008).

In this study, we have analysed the potential diagnostic and prognostic utility of quantifying ECM elements in specimens from 102 primary high-risk NBs with clinical follow-up data using advanced morphometric approaches. We aimed to find different organisations of blood vessels, Ret Fs, Col I Fs and GAGs to define an ultra-high-risk group within the high-risk cohort of children with NB.

\section{MATERIALS AND METHODS}

Samples. We analysed 19 tissue microarrays containing at least two representative cylinders of $1 \mathrm{~mm}$ from 458 primary tumours, referred to the Spanish Reference Centre for NB Biological and Pathological studies (Department of Pathology, University of Valencia) between 1996 and 2007. Histologic and genetic studies were approved by the corresponding committees. Clinical data were provided by the clinicians, histopathology was assessed by a pathologist and genetic information was obtained by fluorescence in situ hybridisation, single-nucleotide polymorphism and static cytometry, following previously published protocols and European guidelines (Shimada et al, 1999; Ambros et al, 2003).

Patients. According to the INRG pretreatment stratification, patients with high-risk disease include those presenting any stage with MYCN amplification; patients with metastatic disease and $\geqslant 18$ months, independently of MYCN status; and patients with metastatic special stage with MYCN non-amplified tumours with 11q deletion (Cohn et al, 2009; Huang and Weiss, 2013). The studied cohort included 102 high-risk patients with a follow-up of at least 60 months for event-free survival (EFS) and 101 high-risk patients with a follow-up of at least 60 months for overall survival (OS). Of these, $80.3 \%$ ( 82 out of 102) of the patients suffered disease progression and $77 \%$ (78 out of 101) died. The median EFS and OS were of $44.5 \pm 5.76$ months (CI 95\% 33.1-55.8) and $61.1 \pm 7.1$ months (CI 95\% 47.0-75.1), respectively. The 5-yearEFS and OS were $24.5 \% \pm 4.3$ and $28.7 \% \pm 4.5$, respectively. Although the criteria to define ultra-high-risk patients are currently under debate, based on current hypotheses, 30 out of 102 patients (29.4\%) who died from disease within 18 months after diagnosis would be considered ultra-high-risk (excluding those with stage 1 with $M Y C N$ amplification and those with metastatic special stage with MYCN non-amplified tumours and 11q deletion, due to treatment heterogeneity in these patient groups). Patients with non-high-risk disease include those with very low, low and intermediate risk, which result from the combination of the stage, the age, the histologic category and grade of differentiation, MYCN non-amplification, the status of $11 \mathrm{q}$ or the overall genetic profile (numerical $v s$ segmental chromosome aberrations) and the ploidy, following the INRG classification (Cohn et al, 2009; Schleiermacher et al, 2012).

Image analysis. The image analysis process and specific settings for each ECM element studied are detailed in Table 1. Serial sections of $3 \mu \mathrm{m}$ were cut and stained. We were interested in quantifying the variations not only in the density, but also in the size and the shape of blood vessels and of Ret Fs, which usually form extended networks. Given that Col I Fs form thick bundles, and GAGs occupy intercellular spaces, both with few morphological changes, we only assessed the percentage of stained area (\%SA) for these elements. The image analysis software provided with the scanner enabled proper segmentation of the GAGs \%SA and the image analysis could therefore be performed directly on the whole-slide scanned image. For the remaining elements, individual images of every sample were exported from the wholeslide scanned image to two computer programs: (1) angiopath (Fernandez-Carrobles et al, 2013; Tadeo et al, 2016), which then closed vessels with incomplete vascular walls to properly quantify the vascular density and to measure variations in the shape and size of the vessels; and (2) Image-Pro Plus 6.0, which enabled proper segmentation of $\mathrm{Col}$ I Fs and provided parameters indicating various morphological features of the Ret Fs networks. JPEG format, with the highest quality compression, was chosen by default as being sufficient to detect image hues without loss of quality, given that the majority of the morphological measurements are not affected by compression (Lopez et al, 2008; Lopez et al, 2009; Lejeune et al, 2011). Nevertheless, we chose TIFF format for blood-vessel analysis because we needed fine segmentation (precise recognition of the elements of interest) to properly perform blood-vessel closing, which is one of the central advantages of the software used. Images were exported using the RGB colour model (for red, green and blue), where a pixel has a component of the three colours ranging from 0 to 255, being 0 the absence of light and 255 full saturated pixels (white), but the HSV colour model (for hue, saturation and value/brightness) was used for blood vessels, providing a more accurate discrimination of the brown hues. The morphometric parameters defining the histological organisation of blood vessels and Ret Fs networks are explained in Table 2.

Statistical methods. The average of all measured parameters was calculated for all elements detected in every single cylinder. We then calculated the mean of the values of the measured parameters of all the cylinders belonging to the same case. The resulting 
Table 1. Description of the image analysis process

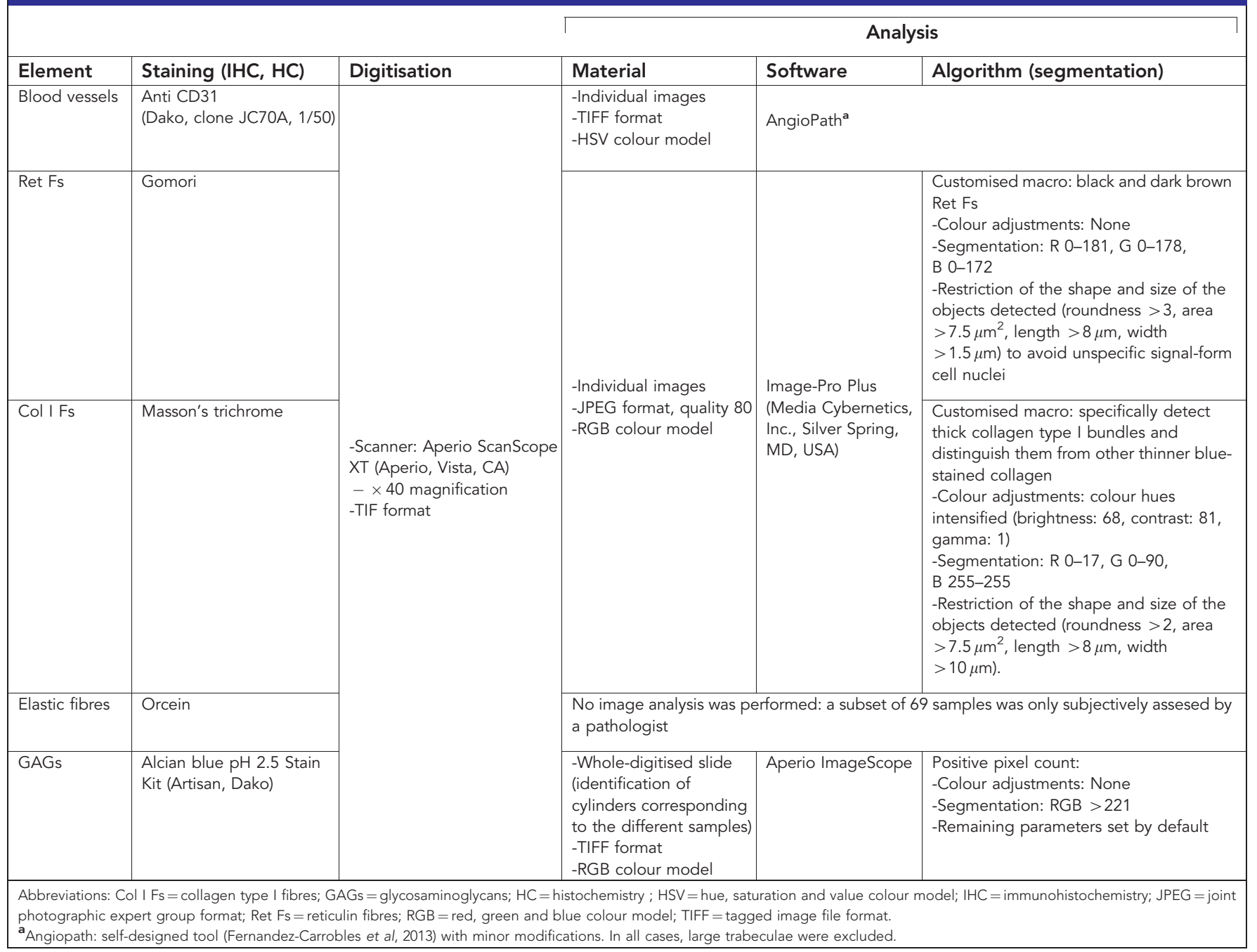

continuous morphometric variables were then dichotomized to perform survival analysis with Kaplan-Meier and log-rank test. The median (Q2) was used, as being the statistically most accurate value, to dichotomise the variables. Nevertheless, as the ultra-highrisk subgroup defined by clinical data was a minority within the high-risk cohort (29.4\%), we also dichotomized using the first quartile (Q1) and the third quartile (Q3), separating the 25\% lowest and highest samples, respectively. $\chi^{2}$ test was used to compare the ultra-high-risk cohort defined by clinical and biological factors and the ultra-high-risk cohort defined by morphometric variables. To test which combination of parameters had the best prognostic value, a Cox regression analysis for survival was used using a log-rank test, and hazard ratio for death using a Wald test. The significance level was established at 95\%. Nonevaluable samples (cylinders lost during the processing, artefacts, non-representative tissue and scant material) were excluded from the analysis. Samples with no immunoreactivity against CD31 which may present vascular mimicry, angiomatoid patterns and focal haemorrhages were also excluded from the statistical analysis (Tadeo et al, 2016).

\section{RESULTS}

Blood-vessel form and size are prognostic. Positive staining of the endothelial cells of blood vessels was found in $88.1 \%$ (74 out of 84 ) of the evaluable samples (material in good conditions and representative of the original tumour tissue, 84 out of 102). All of these samples presented capillaries (5-15 $\mu \mathrm{m}$ diameter), $84.5 \%$ (71 out of 84 ) had postcapillary venules and metarterioles (15-20 $\mu \mathrm{m}$ diameter; venules with pericytes and initial segment of the thoroughfares channels with precapillary sphincters, respectively), $83.3 \%$ (70 out of 84$)$ showed sinusoids or discontinuous capillaries (20-50 $\mu \mathrm{m}$ diameter), $66.6 \%$ (56 out of 84) presented venules and arterioles (50-200 $\mu \mathrm{m}$ diameter), and only $13.0 \%$ (11 out of 84 ) of the samples exhibited small veins and arteries ( $>200 \mu \mathrm{m}$ diameter). Images of typical non-high-risk, high-risk and ultra-high-risk patient samples immunostained with anti-CD31 and the resulting segmentation are shown in Figure 1A-C. Morphometric parameters defining the histological organisation of the blood vessels are explained in Table 2.

An irregular blood-vessel shape (shape factor $>Q 1$ ), and small sinusoids (area $\leqslant$ Q2) defined high-risk patient subgroups with $<10 \%$ 5-year EFS. Regarding OS, high-risk patient subgroups with $<10 \% 5$-year OS were defined by a smaller size (area $\leqslant$ Q2) and an irregular outline (roundness $>$ Q1) of venules and arterioles. The corresponding Kaplan-Meier graphs are shown in Figure 2A-D and the associated data area shown in Table 3A-D. No differences were found in EFS and OS for high-risk patients regarding the morphometric variables of capillaries, and postcapillary venules and metarterioles. Kaplan-Meier graphs and statistical data are not provided. Using this approach alone and considering only 
Table 2. Description of the morphometric variables

\begin{tabular}{|c|c|c|c|c|}
\hline \multirow[b]{2}{*}{ Parameter } & \multicolumn{2}{|c|}{ Blood vessels } & \multicolumn{2}{|c|}{ Reticulin fibres } \\
\hline & Low & High & Low & High \\
\hline \multicolumn{5}{|l|}{ Quantity } \\
\hline Density & $\begin{array}{c}\circ \circ \\
\text { Low density }\end{array}$ & $\begin{array}{c}\circ \mathrm{O}^{\circ} \\
\text { High density }\end{array}$ & Low density & High density \\
\hline Stained area (SA) & $\mathrm{O}_{\text {Reduced SA }}$ & $\mathrm{O}_{\text {Wide SA }}$ & $\begin{array}{l}1 \stackrel{2}{1}{ }^{2} \\
\text { Reduced SA }\end{array}$ & $\begin{array}{l}2 \\
\text { Wide SA }\end{array}$ \\
\hline \multicolumn{5}{|l|}{ Size } \\
\hline Area & Small & Large & Small & Large \\
\hline Length & $\stackrel{\rightleftarrows}{\text { Short }}$ & $\varlimsup_{\text {Long }}^{\longleftarrow}$ & Short & Long \\
\hline Width & Thin & Thick & Thin & Thick \\
\hline Perimeter & Small & Large & \multicolumn{2}{|c|}{ Not applicable } \\
\hline \multicolumn{5}{|l|}{ Shape } \\
\hline Aspect ${ }^{a}$ & Round & Ovoid & Crosslinked networks & $\begin{array}{l}\text { Mostly individual } \\
\text { fibres }\end{array}$ \\
\hline Roundness ${ }^{\text {b,c }}$ & Few protrusions & Abundant protrusion & Low crosslinking & High crosslinking \\
\hline Perimeter ratio ${ }^{c, d}$ & Wavy outline & Smooth outline & Wavy outline & Smooth outline \\
\hline Deformity ${ }^{c, e}$ & Weak deformity & Strong deformity & \multicolumn{2}{|c|}{ Not applicable } \\
\hline Shape factor ${ }^{c, f}$ & Regular & Irregular & \multicolumn{2}{|c|}{ Not applicable } \\
\hline Factal dimension & \multicolumn{2}{|c|}{ Not applicable } & Ordered & Haphazardly arranged \\
\hline Branching & $P_{\text {Unbranched }}$ & Branched & Low branching & High branching \\
\hline
\end{tabular}

Parameters in purple are those with prognostic implications.

${ }^{a}$ Aspect: major axis/minor axis (of ellipse equivalent to the vessel).

b $_{\text {Roundness: perimeter }}^{2} /(4 \times \pi \times a r e a)$.

${ }^{c}$ All these parameters provide information about the degree of deviation from a round and regular elements, using different approaches.

d Perimeter ratio: convex contour perimeter/perimeter (convex contour: outline of the polygon best-fitting to the real shape).

Deformity: convex contour area-area $\left(\mu \mathrm{m}^{2}\right)$.

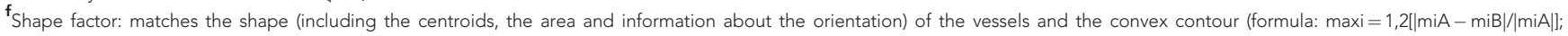
$\mathrm{mi} A / B=\operatorname{sign}(\mathrm{hi} / \mathrm{B}) \cdot \log (\mathrm{hi} A) ; \mathrm{A} / \mathrm{B}=$ Hu moments of real contour/convex contour; $i=$ seven Hu invariant). 


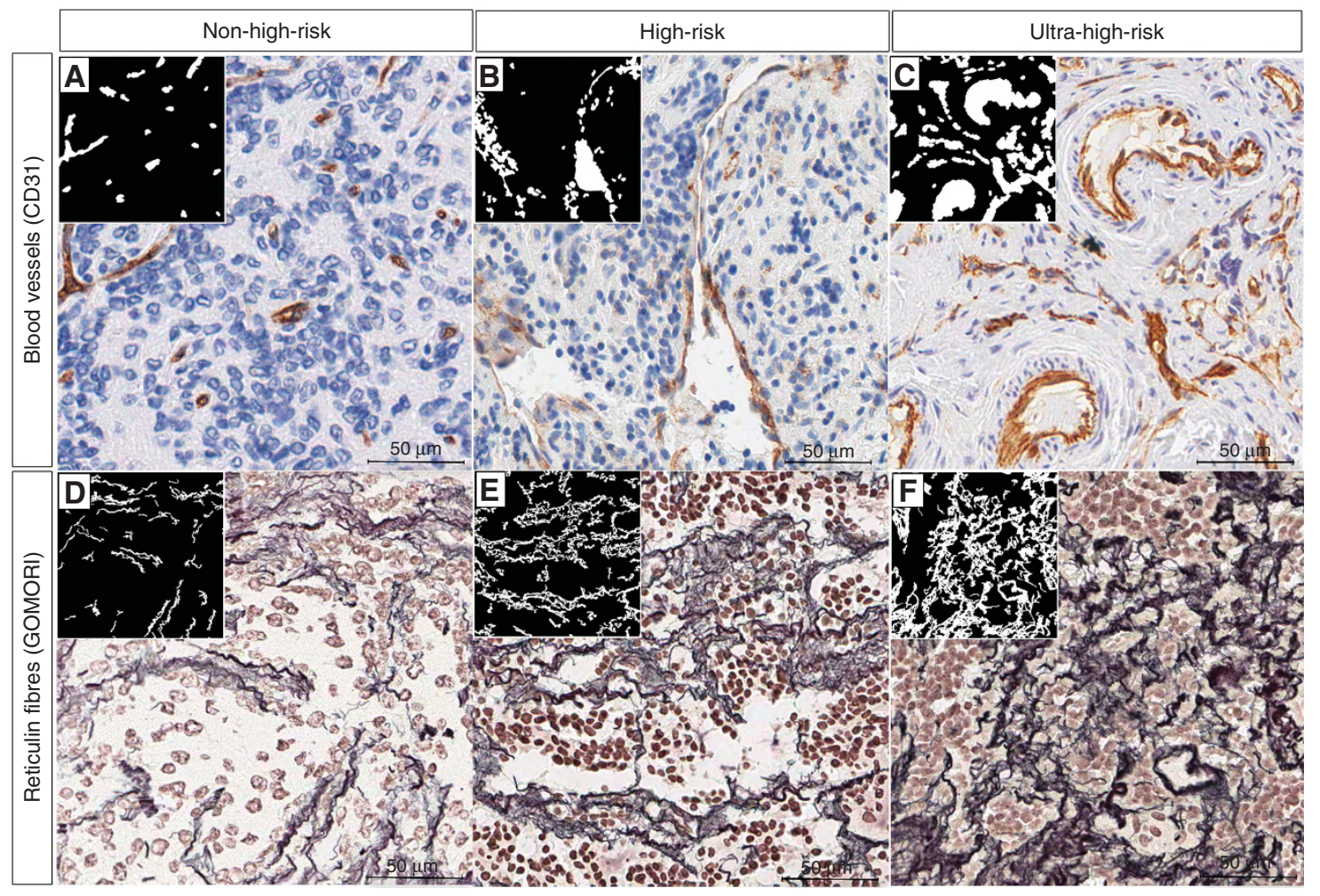

Figure 1. Examples and schematic representations showing how blood vessels and Ret Fs behave in the ECM of non-high-risk, high-risk and ultra-high-risk patients. Ret Fs and blood-vessel binarized images are shown in small squares. (A) Non-high-risk sample with predominant capillaries and scant presence and irregularity of sinusoids. (B) High-risk sample with predominantly large sinusoids. (C) Ultra-high-risk sample with irregularly shaped blood vessels, small and abundant sinusoids and small and very irregular venules and arterioles (arterioles in this specific sample). (D) Non-high-risk sample with reduced \%SA, low crosslinking and smooth outlines. (E) High-risk sample with curvy, crosslinked and nonordered Ret Fs network. (F) Ultra-high-risk sample with much more haphazardly arranged and cross-linked Ret Fs networks, forming a less porous and stiffer ECM. Data corresponding to non-high-risk patients are not shown.

morphometric variables influencing EFS, $86.9 \%$ (73 out of 84 ) of the high-risk patients would have been classified as ultra-high-risk patients. These were patients with ECM hosting irregular blood vessels in general and/or small sinusoids.

Dense and large meshworks of Ret Fs hold prognostic information. Ret Fs were assessed in $82.3 \%$ of the high-risk patient samples (84 out of 102). High-risk patient subgroups with ultra-poor prognosis (mostly under $10 \%$ of 5-year EFS) were robustly defined by the density and the organisation of Ret Fs. Images of typical non-high-risk, high-risk and ultra-high-risk samples stained with Gomori and the resulting segmented Ret Fs are shown in Figure 1D-F. Morphometric parameters defining the histological organisation of the Ret Fs networks are explained in Table 2. Samples with Ret Fs occupying a wide proportion of the tumour tissue (\%SA $>$ Q2), forming large networks (width $>$ Q2) depicting a crosslinked (roundness $>$ Q2), wavy (perimeter ratio $<$ Q2), haphazardly arranged (fractal dimension $>$ Q2) and branched (branching $>$ Q2) network, presented mostly $<10 \%$ of 5-year EFS. The Kaplan-Meier graphs and the associated data are shown in Figure 2E-J and the associated data are presented in Table 3E-J. These results were also found for OS (data not shown). Using this approach alone, considering all Ret Fs morphometric variables for being all related to EFS, $73.8 \%$ (62 out of 84 ) of the high-risk patients would have been classified as ultra-high-risk patients. Considering the two approaches, blood vessels (irregular shape blood vessels and small sinusoids) and Ret Fs (all morphometric variables), together, $39.1 \%$ of patients classified as ultra-high-risk were common to both tools. Additionally, among all the tumour vascularisation and tumour ECM features tested individually, Ret Fs extension (\%SA) is the one with the highest impact on survival, with the lowest $P$-value $(P=0.001)$.

A morphometric classifier is proposed discriminating ultrahigh-risk patients who die within $\mathbf{2 4}$ months. We combined both image analysis tools to define a morphometric classifier. For that purpose, only variables which were related to EFS were considered. Blood-vessel shape factor was omitted from this classification as it included $75 \%$ of the samples in the ultra-high-risk group (data over the Q1 value), and was not considered a discriminative variable. The presence of at least any two of the seven remaining morphometric features (any combination of sinusoids size and/or the six Ret Fs morphometric variables) defined ultra-poor prognosis. Therefore, we grouped high-risk patients according to the number of ultra-high-risk morphometric features presented: those presenting $0-1$ features $(n=26 / 84,31 \%)$ and those presenting at least 2 morphometric features $(n=58 / 84,69 \%)$, the latter thus defining patients with ultra-high-risk of progression. According to the Cox regression, the presence of a large \%SA followed by small sinusoids had the best prognostic value (Table 4). The morphometric classifier identified 25 of the 30 patients (83.3\%) who would be considered ultra-high-risk based on current hypotheses (patients who die within 18 months; $P$-value 0.029 , Spearman correlation 0.230 ). In addition, 33 out of 54 patients (61\%) at present considered as non-ultra-high-risk would also be considered as ultra-high-risk patients following the morphometric classification. Indeed, these patients presented ultra-high-risk of progression, with a mean survival time of 24 months. The Kaplans-Meier curves for both classifications are shown in Figure $2 \mathrm{~K}$ and $\mathrm{L}$ and the associated survival data are shown in Table $3 \mathrm{~K}$ and $\mathrm{L}$. 

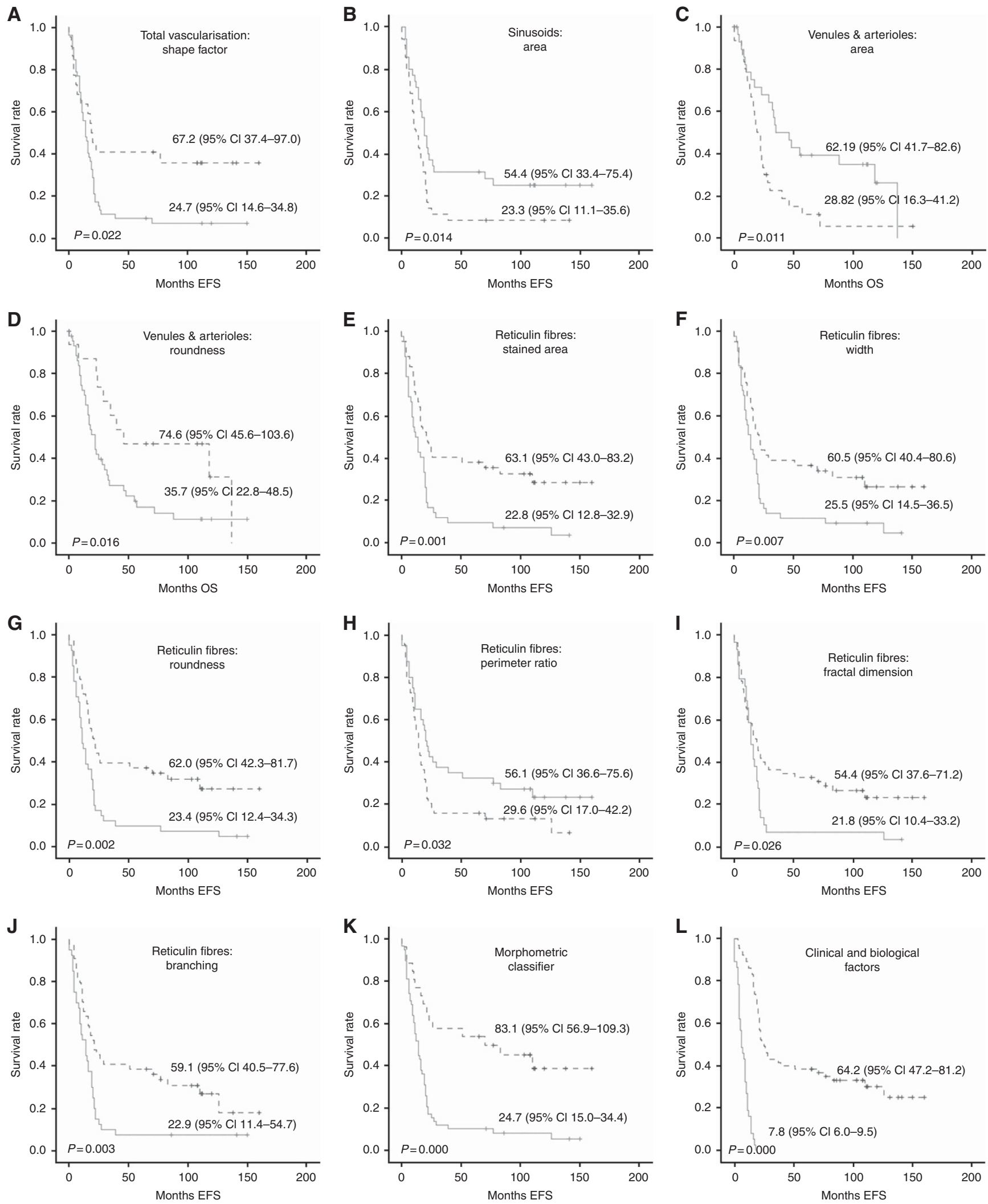

Figure 2. Kaplan-Meier graphs showing the different accumulated EFS or OS depending on different variables. In all cases, the straight line corresponds to the group under the data used for dichotomization, and the discontinuous line corresponds to the group over the data used of dichotomization. These data are shown in Table 3. P-values and survival rates are shown. (A-D) Blood vessels morphometric variables. (A) Shape factor of total blood vascularisation. (B) Area of sinusoids. (C) Area of venules and arterioles. (D) Roundness of venules and arterioles. (E-J) Ret Fs morphometric variables. (E) SA. (F) Width. (G) Roundness. (H) Perimeter ratio. (I) Fractal dimension. (J) Branching. (K) Patients grouped depending of the amount of morphometric variables related to ultra-high-risk of progression. (L) Definition of ultra-high-risk patients according to clinical and biological factors (definition currently under debate). 
Table 3. Survival data of the morphometric variables with prognostic impact

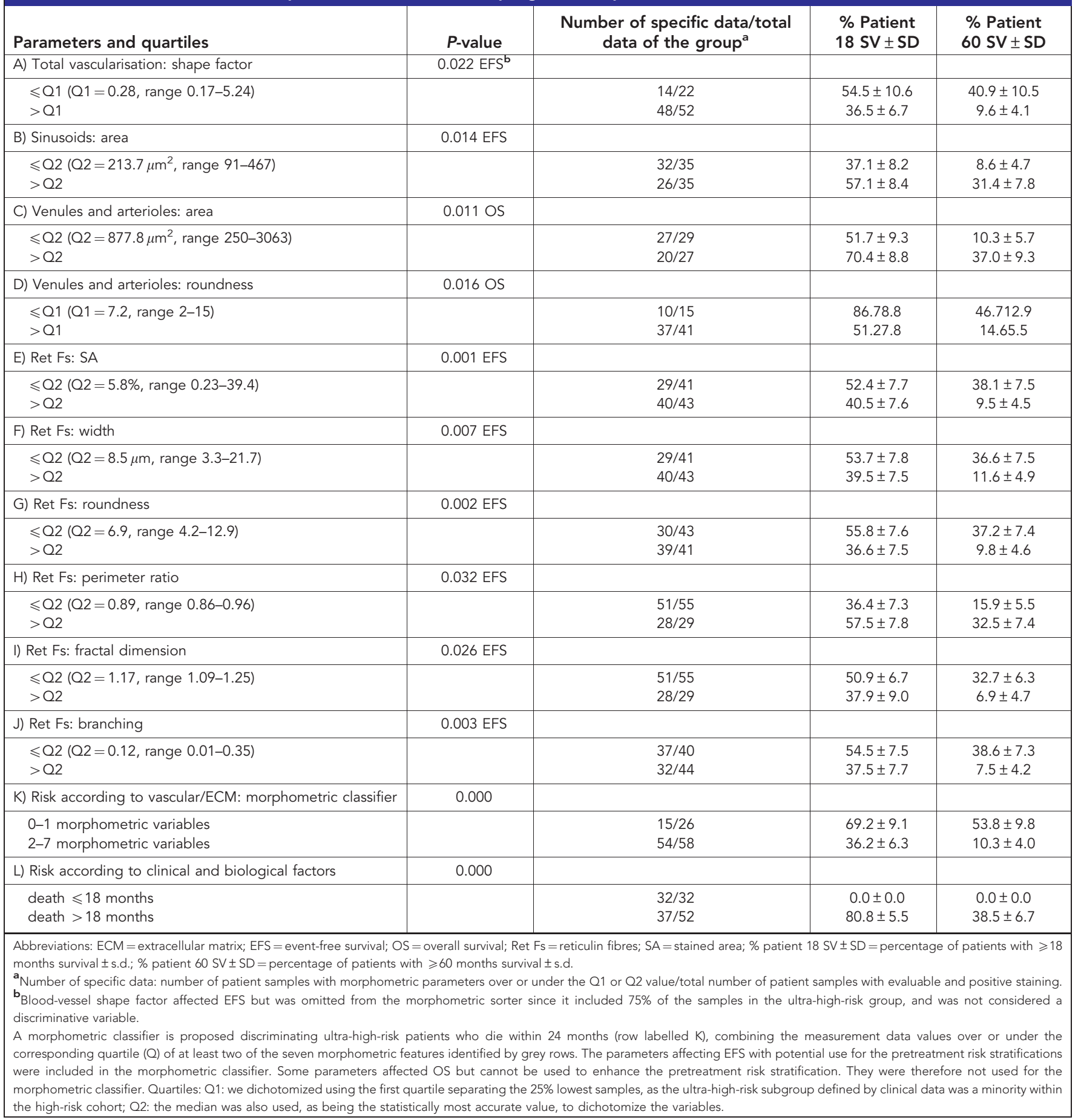

Table 4. Results of the multivariate Cox regression showing the influence of the vascular and ECM morphometric parameters on survival

\begin{tabular}{|l|c|c|}
\hline Parameters & Hazar ratio $(\mathbf{9 5 \%} \mathrm{Cl})$ & $\boldsymbol{P}$-value \\
\hline Ret Fs: high SA & $2.13(1.22-3.72)$ & 0.007 \\
\hline Sinusoids: small area & $0.61(0.35-1-05)$ & 0.077 \\
\hline $\begin{array}{l}\text { Abbreviations: } \mathrm{Cl}=\text { confidence interval; } \mathrm{ECM}=\text { extracellular matrix; Ret Fs = reticulin fibres; } \\
\text { SA=stained area. }\end{array}$
\end{tabular}

Col I Fs, EFs and GAGs are not informative in defining NB high-risk patients. The amount of Col I Fs and GAGs did not show any influence on survival in our high-risk cohort.
The amount of EF was negligible, except for vascular distant laminas in the blood-vessel walls. Kaplan-Meier graphs and statistical data are not provided.

\section{DISCUSSION}

By introducing advanced morphometric methodology, we have been able to demonstrate and robustly quantify ECM components in a large cohort of NB samples. The prognostic classification of ultra-high-risk NB patients is currently under debate (SaarinenPihkala et al, 2013; Pinto et al, 2015). The data show that the 
morphology of blood vessels has a bearing on the behaviour of high-risk NB patients, and also that Ret Fs network abundance and morphology in high-risk NB specimens is linked to high-risk patient outcome. Our data suggest that identifying precise mechanisms behind Ret Fs and blood-vessel organisation might be a future avenue for treatment of ultra-high-risk NBs.

Morphometric techniques assure the standardisation of all measurements and minimise inter-observer differences (Nast et al, 2015). It has been shown that nuclear texture automated analysis can help to discriminate between different differentiated small round cell tumours (Garcia-Bonafe and Moragas, 1995). In addition, computer-based grading systems already support diagnosis and discriminate stroma-poor, and stroma-rich regions in NB (Kong et al, 2008; Gurcan et al, 2009; Sertel et al, 2009). The development of statistical modelling recently enabled our group to describe the prognostic value of ECM elements, neuroblastic cell markers and vascular patterns to establish the degree of influence on NB patient outcome (Tadeo et al, 2013, 2016). In this study, by introducing advanced morphometric methodology, we have been able to robustly quantify ECM components in a wide set of high-risk NB.

To our knowledge, the influence of the morphology of the blood vascularisation and fibrous scaffolding on prognosis in high-risk $\mathrm{NB}$ patients has not been investigated previously. In general, tumour blood vessels are known to be highly disorganised, tortuous and dilated, with uneven diameter, excessive branching and shunts (Carmeliet and Jain, 2000). In the high-risk cohort studied, not only irregularly shaped blood vessels in general, but also small sinusoid-like vessels, and small venules and arterioles with abundant protrusions define subgroups of patients with ultrapoor prognosis within the high-risk cohort. In addition, in our cohort, morphometric parameters defining an anarchic network of Ret Fs, with high crosslinking, and therefore correlating with a stiff ECM, also define ultra-high-risk subgroups. Both an abnormal morphology of tumour blood vessels and an increased stiffness have been described to result in a hostile tumour microenvironment that facilitates disease progression and the distribution of chemotherapeutics (Jain and Baxter, 1988; Afratis et al, 2012; Salmon et al, 2012; Ariffin et al, 2014). Our data suggest that identifying ECM organisation variations might be a future avenue for stratification. In fact, the combination of the morphometric parameters of blood vessels and Ret Fs enabled the proper identification of a large majority of the ultra-high-risk patients provisionally defined by clinical and biological factors, plus a set of patients which would not currently be considered as ultra-high-risk, but indeed presented very poor survival. This system provides an accurate and extended definition of ultra-highrisk NB patients.

The fact that blood vessel and Ret Fs composition and organisation in NB are prognostic opens up for the possibility of developing new therapies that target the mechanisms leading to aberrant behaviour of ECM components. In this regard, multiple direct angiogenic inhibitors (angiostatin, endostatin and thrombospondin) targeting endothelial cells and indirect antiantiangiogenic agents blocking the production or activity of proangiogenic molecules, such as VEGF, have been developed (Rossler et al, 2008). However, recent studies have focused on the value of normalising tumour vasculature to improve response to conventional anticancer therapies, rather than destroying tumour vessels to starve primary tumours from oxygen and induce tumour shrinkage (Tong et al, 2004; Salnikov et al, 2006; Carmeliet and Jain, 2011). This normalised tumour vasculature becomes less permeable and tortuous with their normal function restored (Jain et al, 2007; Goel et al, 2012). Strategies focusing on the reversal of existing fibrosis could also be developed (Zeisberg and Kalluri, 2013; Tsou et al, 2014). Collagenase has been shown to decrease stiffness by cleaving collagen and consequently destroying the collagen crosslinked networks in tumours in human osteosarcoma xenografts (Eikenes et al, 2004). Another therapeutic approach not affecting the amount of fibres, but affecting morphology, would be to impede crosslinking by the monoclonal antibody AB0023 (Barry-Hamilton et al, 2010). Our methodology might also be useful to explore the effects of these therapies.

In summary, our data show that combing the morphological parameters of irregularly shaped blood vessels, and a stiff Ret Fs network with increased crosslinking and branching, can be useful to predict survival in the high-risk NB patient cohort and to identify an ultra-high-risk group. Because of their importance to tumour aggressiveness, the presented findings offer a new spectrum of therapeutic opportunities whose application in NB should be considered. Both the grading and the therapeutic aspects should be confirmed after validation of the results on a larger highrisk patient cohort.

Ethical considerations. Histologic and genetic studies were approved by the Spanish Society of Pediatric Hematology and Oncology (file number: 59C18ABR2002), Ministry of Health (ISCIII; file number: H1270128195640) and European Committee (file number: 2010-021396-81), as well as by the Ethical Committee of the University of Valencia. Participants or their family members/informants signed written informed consent forms for histological and genetic studies. The samples were stored at the Pathology Department biobank, recognised and referred by the ISCIII (reference: B0000339 26/11/2012).

\section{ACKNOWLEDGEMENTS}

We thank Francisco Santonja and José Bermúdez for statistical support and Elisa Alonso for a precious technical support. We also thank the Spanish Society of Pediatric Hemato-Oncology (SEHOP) for patient data management. This study was supported by the FIS contract PI14/01008 and RTICC contracts RD12/0036/0020 and RD12/0036/0027, grants from the ISCIII \& FEDER (European Regional Development Fund), Spain.

CONFLICT OF INTEREST

The authors declare no conflict of interest.

\section{REFERENCES}

Afratis N, Gialeli C, Nikitovic D, Tsegenidis T, Karousou E, Theocharis AD, Pavao MS, Tzanakakis GN, Karamanos NK (2012) Glycosaminoglycans: key players in cancer cell biology and treatment. FEBS J 279: $1177-1197$.

Ambros IM, Benard J, Boavida M, Bown N, Caron H, Combaret V, Couturier J, Darnfors C, Delattre O, Freeman-Edward J, Gambini C, Gross N, Hattinger CM, Luegmayr A, Lunec J, Martinsson T, Mazzocco K, Navarro S, Noguera R, O’Neill S, Potschger U, Rumpler S, Speleman F, Tonini GP, Valent A, Van Roy N, Amann G, De Bernardi B, Kogner P, Ladenstein R, Michon J, Pearson AD, Ambros PF (2003) Quality assessment of genetic markers used for therapy stratification. J Clin Oncol 21: $2077-2084$.

Ambros PF, Ambros IM, Brodeur GM, Haber M, Khan J, Nakagawara A, Schleiermacher G, Speleman F, Spitz R, London WB, Cohn SL, Pearson AD, Maris JM (2009) International consensus for neuroblastoma molecular diagnostics: report from the International Neuroblastoma Risk Group (INRG) Biology Committee. Br J Cancer 100: 1471-1482.

Ariffin AB, Forde PF, Jahangeer S, Soden DM, Hinchion J (2014) Releasing pressure in tumors: what do we know so far and where do we go from here? A review. Cancer Res 74: 2655-2662. 
Barry-Hamilton V, Spangler R, Marshall D, McCauley S, Rodriguez HM, Oyasu M, Mikels A, Vaysberg M, Ghermazien H, Wai C, Garcia CA, Velayo AC, Jorgensen B, Biermann D, Tsai D, Green J, Zaffryar-Eilot S, Holzer A, Ogg S, Thai D, Neufeld G, Van Vlasselaer P, Smith V (2010) Allosteric inhibition of lysyl oxidase-like-2 impedes the development of a pathologic microenvironment. Nat Med 16: 1009-1017.

Bergers G, Benjamin LE (2003) Tumorigenesis and the angiogenic switch. Nat Rev Cancer 3: 401-410.

Canete A, Navarro S, Bermudez J, Pellin A, Castel V, Llombart-Bosch A (2000) Angiogenesis in neuroblastoma: relationship to survival and other prognostic factors in a cohort of neuroblastoma patients. J Clin Oncol 18: $27-34$

Carmeliet P, Jain RK (2000) Angiogenesis in cancer and other diseases. Nature 407: 249-257.

Carmeliet P, Jain RK (2011) Principles and mechanisms of vessel normalization for cancer and other angiogenic diseases. Nat Rev Drug Discov 10: 417-427.

Cohn SL, Pearson AD, London WB, Monclair T, Ambros PF, Brodeur GM, Faldum A, Hero B, Iehara T, Machin D, Mosseri V, Simon T, Garaventa A, Castel V, Matthay KK (2009) The International Neuroblastoma Risk Group (INRG) classification system: an INRG Task Force report. J Clin Oncol 27: 289-297.

Devy J, Duca L, Cantarelli B, Joseph-Pietras D, Scandolera A, Rusciani A, Parent L, Thevenard J, Pasco SB, Tarpin M, Martiny L, Debelle L (2012) Elastin-derived peptides enhance melanoma growth in vivo by upregulating the activation of Mcol-A (MMP-1) collagenase. Br J Cancer 103: $1562-1570$.

DuFort CC, Paszek MJ, Weaver VM (2010) Balancing forces: architectural control of mechanotransduction. Nat Rev Mol Cell Biol 12: 308-319.

Eikenes L, Bruland OS, Brekken C, Davies Cde L (2004) Collagenase increases the transcapillary pressure gradient and improves the uptake and distribution of monoclonal antibodies in human osteosarcoma xenografts. Cancer Res 64: 4768-4773.

Fernandez-Carrobles MM, Tadeo I, Bueno G, Noguera R, Deniz O, Salido J, Garcia-Rojo M (2013) TMA vessel segmentation based on color and morphological features: application to angiogenesis research. ScientificWorldJournal 2013: 263190.

Folkman J, Merler E, Abernathy C, Williams G (1971) Isolation of a tumor factor responsible for angiogenesis. J Exp Med 133: 275-288.

Garcia-Bonafe M, Moragas A (1995) Nuclear texture in poorly differentiated small round cell tumors. Image analysis study of fine needle aspiration material. Anal Quant Cytol Histol 17: 189-196.

Goel S, Wong AH, Jain RK (2012) Vascular normalization as a therapeutic strategy for malignant and nonmalignant disease. Cold Spring Harb Perspect Med 2: a006486.

Gurcan MN, Boucheron LE, Can A, Madabhushi A, Rajpoot NM, Yener B (2009) Histopathological image analysis: a review. IEEE Rev Biomed Eng 2: 147-171.

Hu M, Polyak K (2008) Microenvironmental regulation of cancer development. Curr Opin Genet Dev 18: 27-34.

Huang M, Weiss WA (2013) Neuroblastoma and MYCN. Cold Spring Harb Perspect Med 3: a014415.

Jain RK, Baxter LT (1988) Mechanisms of heterogeneous distribution of monoclonal antibodies and other macromolecules in tumors: significance of elevated interstitial pressure. Cancer Res 48: 7022-7032.

Jain RK, Tong RT, Munn LL (2007) Effect of vascular normalization by antiangiogenic therapy on interstitial hypertension, peritumor edema, and lymphatic metastasis: insights from a mathematical model. Cancer Res 67: 2729-2735.

Jakovljevic G, Culic S, Stepan J, Kosuta I, Seiwerth S (2011) Relationship between tumor vascularity and vascular endothelial growth factor as prognostic factors for patients with neuroblastoma. Coll Antropol 35: 1071-1079.

Karamanos NK, Tzanakakis GN (2012) Glycosaminoglycans: from "cellular glue" to novel therapeutical agents. Curr Opin Pharmacol 12: 220-222.

Kong J, Sertel O, Boyer KL, Saltz JH, Gurcan MN, Shimada H (2008) Computer-assisted grading of neuroblastic differentiation. Arch Pathol Lab Med 132: 903-904; author reply 904.

Lam WA, Cao L, Umesh V, Keung AJ, Sen S, Kumar S (2010) Extracellular matrix rigidity modulates neuroblastoma cell differentiation and $\mathrm{N}$-myc expression. Mol Cancer 9: 35.

Lejeune M, Lopez C, Bosch R, Korzynska A, Salvado MT, Garcia-Rojo M, Neuman U, Witkowski L, Baucells J, Jaen J (2011) JPEG2000 for automated quantification of immunohistochemically stained cell nuclei: a comparative study with standard JPEG format. Virchows Arch 458: 237-245.

Li GN, Livi LL, Gourd CM, Deweerd ES, Hoffman-Kim D (2007)

Genomic and morphological changes of neuroblastoma cells in response to three-dimensional matrices. Tissue Eng 13: 1035-1047.

Liu S, Tian Y, Chlenski A, Yang Q, Salwen HR, Cohn SL (2005) 'Cross-talk' between Schwannian stroma and neuroblasts promotes neuroblastoma tumor differentiation and inhibits angiogenesis. Cancer Lett 228: 125-131.

Lopez C, Jaen Martinez J, Lejeune M, Escriva P, Salvado MT, Pons LE, Alvaro T, Baucells J, Garcia-Rojo M, Cugat X, Bosch R (2009) Roundness variation in JPEG images affects the automated process of nuclear immunohistochemical quantification: correction with a linear regression model. Histochem Cell Biol 132: 469-477.

Lopez C, Lejeune M, Escriva P, Bosch R, Salvado MT, Pons LE, Baucells J, Cugat X, Alvaro T, Jaen J (2008) Effects of image compression on automatic count of immunohistochemically stained nuclei in digital images. J Am Med Inform Assoc 15: 794-798.

Lovett DB, Shekhar N, Nickerson JA, Roux KJ, Lele TP (2013) Modulation of nuclear shape by substrate rigidity. Cell Mol Bioeng 6: 230-238.

Lowery JL, Datta N, Rutledge GC (2010) Effect of fiber diameter, pore size and seeding method on growth of human dermal fibroblasts in electrospun poly(epsilon-caprolactone) fibrous mats. Biomaterials 31: 491-504.

Maiese K (2012) The many facets of cell injury: angiogenesis to autophagy. Curr Neurovasc Res 9: 83-84.

Nast CC, Lemley KV, Hodgin JB, Bagnasco S, Avila-Casado C, Hewitt SM, Barisoni L (2015) Morphology in the digital age: integrating highresolution description of structural alterations with phenotypes and genotypes. Semin Nephrol 35: 266-278.

Ng MR, Brugge JS (2009) A stiff blow from the stroma: collagen crosslinking drives tumor progression. Cancer Cell 16: 455-457.

Padera TP, Stoll BR, Tooredman JB, Capen D, di Tomaso E, Jain RK (2004) Pathology: cancer cells compress intratumour vessels. Nature 427: 695.

Peddinti R, Zeine R, Luca D, Seshadri R, Chlenski A, Cole K, Pawel B, Salwen HR, Maris JM, Cohn SL (2007) Prominent microvascular proliferation in clinically aggressive neuroblastoma. Clin Cancer Res 13: 3499-3506.

Pinto NR, Applebaum MA, Volchenboum SL, Matthay KK, London WB, Ambros PF, Nakagawara A, Berthold F, Schleiermacher G, Park JR, Valteau-Couanet D, Pearson AD, Cohn SL (2015) Advances in risk classification and treatment strategies for neuroblastoma. J Clin Oncol 33: 3008-3017.

Ren YJ, Zhang S, Mi R, Liu Q, Zeng X, Rao M, Hoke A, Mao HQ (2013) Enhanced differentiation of human neural crest stem cells towards the Schwann cell lineage by aligned electrospun fiber matrix. Acta Biomater 9: $7727-7736$.

Rossler J, Taylor M, Geoerger B, Farace F, Lagodny J, Peschka-Suss R, Niemeyer CM, Vassal G (2008) Angiogenesis as a target in neuroblastoma. Eur J Cancer 44: 1645-1656.

Saarinen-Pihkala UM, Jahnukainen K, Wikstrom S, Koivusalo A, Karikoski R, Sariola H, Hovi L (2013) Ultrahigh-risk group within the high-risk neuroblastoma category. J Pediatr Hematol Oncol 35: e254-e259.

Salmon H, Franciszkiewicz K, Damotte D, Dieu-Nosjean MC, Validire P, Trautmann A, Mami-Chouaib F, Donnadieu E (2012) Matrix architecture defines the preferential localization and migration of $\mathrm{T}$ cells into the stroma of human lung tumors. J Clin Invest 122: 899-910.

Salnikov AV, Heldin NE, Stuhr LB, Wiig H, Gerber H, Reed RK, Rubin K (2006) Inhibition of carcinoma cell-derived VEGF reduces inflammatory characteristics in xenograft carcinoma. Int J Cancer 119: 2795-2802.

Schleiermacher G, Mosseri V, London WB, Maris JM, Brodeur GM, Attiyeh E, Haber M, Khan J, Nakagawara A, Speleman F, Noguera R, Tonini GP, Fischer M, Ambros I, Monclair T, Matthay KK, Ambros P, Cohn SL, Pearson AD (2012) Segmental chromosomal alterations have prognostic impact in neuroblastoma: a report from the INRG project. $\mathrm{Br} J$ Cancer 107: 1418-1422.

Sertel O, Kong J, Shimada H, Catalyurek UV, Saltz JH, Gurcan MN (2009) Computer-aided prognosis of neuroblastoma on whole-slide images: classification of stromal development. Pattern Recognit 42: 1093-1103.

Shimada H, Ambros IM, Dehner LP, Hata J, Joshi VV, Roald B, Stram DO, Gerbing RB, Lukens JN, Matthay KK, Castleberry RP (1999) The international neuroblastoma pathology classification (the Shimada system). Cancer 86: 364-372. 
Tadeo I, Bueno G, Berbegall AP, Fernandez-Carrobles MM, Castel V, Garcia-Rojo M, Navarro S, Noguera R (2016) Vascular patterns provide therapeutic targets in aggressive neuroblastic tumors. Oncotarget; e-pub ahead of print 24 February 2016; doi:10.18632/oncotarget.7661.

Tadeo I, Piqueras M, Montaner D, Villamon E, Berbegall AP, Canete A, Navarro S, Noguera R (2013) Quantitative modeling of clinical, cellular, and extracellular matrix variables suggest prognostic indicators in cancer: a model in neuroblastoma. Pediatr Res 75: 302-314.

Tong RT, Boucher Y, Kozin SV, Winkler F, Hicklin DJ, Jain RK (2004) Vascular normalization by vascular endothelial growth factor receptor 2 blockade induces a pressure gradient across the vasculature and improves drug penetration in tumors. Cancer Res 64: 3731-3736.

Toupance S, Brassart B, Rabenoelina F, Ghoneim C, Vallar L, Polette M, Debelle L, Birembaut P (2012) Elastin-derived peptides increase invasive capacities of lung cancer cells by post-transcriptional regulation of MMP-2 and uPA. Clin Exp Metastasis 29: 511-522.
Tsou PS, Haak AJ, Khanna D, Neubig RR (2014) Cellular mechanisms of tissue fibrosis. 8. Current and future drug targets in fibrosis: focus on Rho GTPase-regulated gene transcription. Am J Physiol Cell Physiol 307: C2-C13.

Ushiki T (2002) Collagen fibers, reticular fibers and elastic fibers. A comprehensive understanding from a morphological viewpoint. Arch Histol Cytol 65: 109-126.

Zeisberg M, Kalluri R (2013) Cellular mechanisms of tissue fibrosis. 1. Common and organ-specific mechanisms associated with tissue fibrosis. Am J Physiol Cell Physiol 304: C216-C225.

This work is published under the standard license to publish agreement. After 12 months the work will become freely available and the license terms will switch to a Creative Commons AttributionNonCommercial-Share Alike 4.0 Unported License. 